\title{
BIOLOGICAL ASSESSMENT OF AERIAL FOREST SPRAYING AGAINST THE SPRUCE BUDWORM IN NEW BRUNSWICK \\ 1. TIMING OF OPERATIONS $1952-54^{1}$
}

\author{
F. E. WEBB ${ }^{2}$
}

$A$ native of Saskatchewan, Frank $E$. Webb served six years in the R.A.F. and R.C.A.F. Following graduation with the degree of B.SC.F. from the University of New Brunswick in 1949, he joined the Forest Biology Laboratory at Fredericton. Proceeding to graduate studies at the University of Michigan, he received the degrees of M.F. and Ph.D. in 1950 and 1953, respectively, for ecological studies of the larch casebearer in the Maritime Provinces and the Lake States. While at U.N.B., he was the recipient of C.W. L. Jones and Price Bros. forestry scholarships and at Michigan held a University Fellowship for two years in addition to lecturing in Forest Entomology for a semester. Since 1952 he has conducted studies of the effects of aerial spraying against the spruce budworm in New Brunswick.

\section{$A B S T R A C T$}

The aerial spraying operations in New Brunswick against the spruce budworm have involved large areas in which tree mortality was imminent. In working out practical methods of timing applications, consideration has been given to the protection of foliage as well as to the immediate reduction of budworm populations. Modifications in operational techniques to lower spraying costs and increase area coverage have necessitated earlier spraying and lighter dosages. Factors considered in the timing include severity of infestation and defoliation, probable amount of spraying weather available, phenological differences between areas, the feeding habits of the budworm, and the tendency of spray to drift. The assessment of development was accomplished mainly by ground studies at representative locations and extended to the area at large by aerial surveys of balsam fir shoot growth.

An analysis is made of spraying effectiveness in relation to timing from field data collected for studying the immediate results. From this, estimates are given of the average number of days during which various levels of rated effectiveness are attainable.

\section{FOREWORD}

The present outbreak of the spruce budworm, Choristoneura fumiferana (Clem.), was first evident over large areas in the central highlands of northern New Brunswick in 1949. By 1951 an area centering on the headwaters of the S. E. Upsalquitch River had become badly defoliated and heavy infestation extended over a total of 2,200 square miles. In 1952 an aerial spraying operation was initiated by the New Brunswick International Paper Co., in co-operation with the New Brunswick Department of Lands and Mines. Three hundred square miles of the most severely attacked forests on the S. E. Upsalquitch

\footnotetext{
${ }^{1}$ Contribution No. 214, Forest Biology Division, Science Service, Department of Agriculture, Ottawa, Canada. Received for publication March 15, 1955.

¿ Forest Biology Laboratory, Fredericton, N.B.
} 
were sprayed from one airstrip $(2,3,4)$. In 1953 and 1954 , operations were continued by Forest Protection Ltd., a Crown company formed by four New Brunswick pulp and paper companies and the Department of Lands and Mines. Costs have been shared in equal thirds between these two groups and the Canadian Government. A total of 2,800 square miles in Restigouche, Gloucester, Northumberland, Victoria, and Madawaska counties was sprayed from six airstrips in 1953 (5). In 1954 the operation covered 1,700 square miles, mostly in Northumberland County, from two new airstrips and three of those previously constructed (19) (Fig. 1). Since 1952 the operations have been planned and directed by B. W. Flieger, Manager of Forest Protection Ltd. Mr. Flieger $(10,11)$ has also been responsible for investigating and adopting improved operational methods that have resulted in lower costs per acre and more effective application of the spray (5).

The Division of Forest Biology has provided technical assistance and advice, and has undertaken the study of immediate results and long-term effects. Reports of immediate results have been made available from time to time $(2,5,19)$ but the analysis of long-term results will not be possible until the outbreak has run its course. Therefore, the first papers of this series will be primarily concerned with the development of techniques and methods of collecting and analysing data.

\section{FaCtors Involved In Trming}

In general, aerial spraying in New Brunswick has been deferred until the risk of timber mortality is imminent. This is considered to take the best advantage of natural control and minimizes the possibility of unnecessary spraying. Indications of impending mortality of budworm-attacked balsam fir have been outlined by Belyea (6) from studies of outbreaks in the Lake Nipigon area of Ontario. Judging by the presence of brown streaks in the cambium near the base of the tree, mortality commenced in the fifth year of severe defoliation and reached a peak after eight years. The first trees to die were generally overtopped saplings and the least vigorous members of the stand. External evidences of distress were heavy shoot mortality, substitution of normal bud production by crops of adventitious buds and dying back of the terminal leader. In advanced stages of distress, bud development was retarded, the growing period had become progressively shorter, and in some cases, the foliage wilted perceptibly. The effects of severe defoliation on the radial growth at the base of the trees were apparently cumulative, since no reduction was evident for at last two years after the first severe attack.

The history of defoliation and growth reduction due to spruce budworm in New Brunswick is complicated by the occurrence of damage from other causes during the early stages of the outbreak. The first severe defoliation in the S. E. Upsalquitch epicentre occurred in 1949 but was preceded by defoliation by the black-headed budworm, Acleris variana (Fern.), in 1948 (16). In 1950 heavy flowering was general on mature fir in northern New Brunswick and undoubtedly was responsible for radial and terminal growth reduction as shown by Morris (13). Severe spring frosts occurred in many areas in 1951, particularly in the S. E. Upsalquitch region, and in combination with the spruce budworm resulted in almost complete destruction of the current shoots. Thus, 


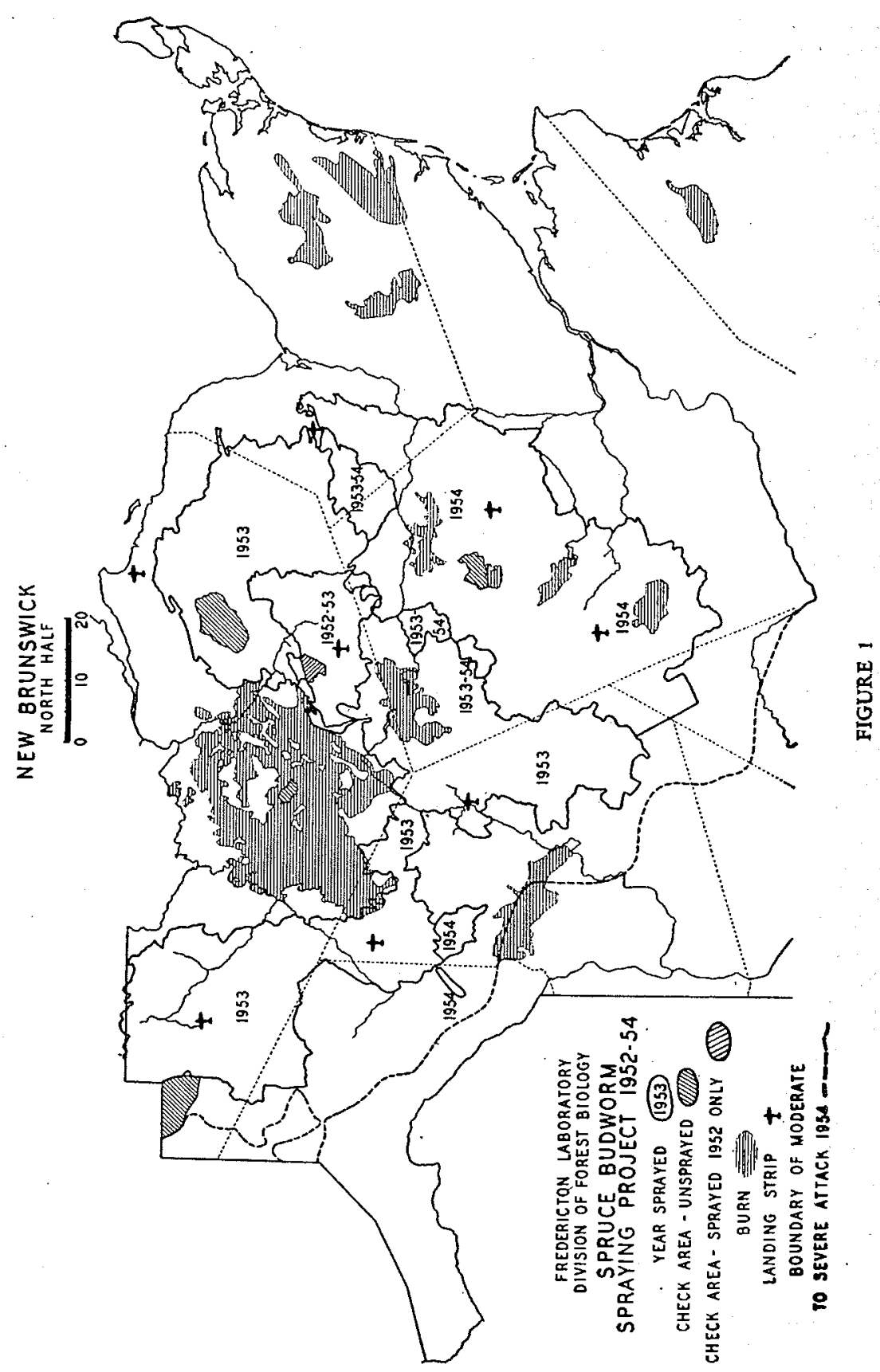


by 1952 , the youngest remaining terminal growth in the most severely affected areas consisted of 1949 twigs. Apart from the temporary reduction in radial growth in the year of heavy flowering, 1950, the first positive indication of decreased diameter growth attributable to the budworm occurred in 1952, although a progressive decline starting in 1950 is evident in some cases. Thus, the 1952 spraying occurred in the fourth year of severe attack, and according to the Ontario results, the year before the first mortality would be expected. Actually, mortality of advanced reproduction (small saplings), overtopped by mature balsam and spruce, commenced as early as 1952 in the sprayed areas, but further mortality of larger trees was apparently prevented by the spraying. In other areas, in which the first severe spruce budworm attack occurred in 1950 , the first mortality of pole size or larger trees, definitely attributable to the budworm, occurred in 1954, the fifth year of attack. These were mainly suppressed or partially suppressed trees and the total mortality from budworm and other causes did not exceed 7 per cent at any location.

Following the general principles outlined above, the three years' operations to date have treated areas of successively younger infestation, in each case three to four years after the initial severe attack. Outbreak boundaries and areas of high hazard have been mapped by large-scale aerial and ground surveys. In addition, assurance of severe attack the following year has been obtained by surveys of egg populations based on a sequential sampling method designed for the purpose by Morris (14). A description of survey techniques will be presented in a subsequent paper.

Under such severe conditions of defoliation, it is apparent that assessments of immediate spraying results should include consideration of the amount of protection given the foliage and growth capacity of the trees as well as the degree of reduction of budworm populations. This has been particularly true in the New Brunswick operations where moth invasions from unsprayed areas have tended to reduce the effect of high larval mortality from spraying. Increasing recognition of the importance of foliage protection has been largely responsible for modifications in spraying techniques in these operations. These have involved lighter dosages, the coverage of larger areas with the same number of planes, earlier applications, and timing to allow for phenological differences between areas as well as to take the maximum advantage of drift.

In planning the 1952 operations, consideration was given to information from previous budworm spraying operations in other parts of Canada and the United States $(8,9,15,17,18)$. Studies made by the United States Bureau of Entomology and Plant Quarantine suggested that the optimum time to commence spraying was when approximately 50 per cent of the larvae were in the fifth instar (1). This was based on the objective of obtaining maximum larval mortality under infestation conditions less severe than those in New Brunswick. The 1952 operation was actually commenced a few days earlier, two days after the peak of the fourth instar, to allow a spraying period of approximately 15 days before 10 per cent of the larvae had pupated. Subsequent sampling showed high mortality on all plots, but only on the earliest-sprayed plots had significant amounts of new foliage been protected (Table 1). On plots sprayed during the latter half of the schedule little or no new foliage remained, and in some cases feeding had commenced 
on the older foliage. Egg surveys after spraying showed more or less uniform reinfestation by moth flights of the whole area to a degree usually sufficient to cause considerable damage to the new foliage the following year. Thus, with heavy egg populations and severe defoliation, the prospects of recurring damage appeared to be quite serious for the late-sprayed plots as well as for adjacent unsprayed areas. Studies in 1953 actually showed good recovery throughout the treated area, but the beneficial effects were most evident in the parts treated first.

TABLE 1

Per Cent Population Reduction from Spraying for Various Dates of Spraying in 1952. Instar DeVelopment: Peak of Fourth Instar, June 12; Peak of Fifth Instar, June 20.

\begin{tabular}{|c|c|c|c|c|c|c|}
\hline $\begin{array}{l}\text { Spraying } \\
\text { period }\end{array}$ & $\begin{array}{l}\text { Mean \% } \\
\text { population } \\
\text { reduction }\end{array}$ & $\frac{\% \text { new }}{\text { Mean }}$ & $\frac{\text { foliage saved }}{\text { Range }}$ & $\frac{\text { Dosage }}{\text { Mean }}$ & $\frac{\text { - g.p.a. }}{\text { Range }}$ & $\begin{array}{l}\text { No. } \\
\text { plots }\end{array}$ \\
\hline June $14-17$ & 99.8 & 15 & $0-75$ & .39 & $.13-.64$ & 10 \\
\hline June $17-22$ & 99.9 & 5 & $0-20$ & .41 & $.22-.66$ & 10 \\
\hline June $23-25$ & 99.9 & 1 & $0-5$ & .24 & $.05-.41$ & 10 \\
\hline
\end{tabular}

In 1953 the application techniques were modified to allow earlier spraying and give lighter average dosages $(5,10)$. Planes were flown in pairs 250 feet part, with 150 feet between flight lines. This resulted in half the previous dosage of one pound of DDT in one U.S. gallon of solvent per acre. Provision was made for respraying areas inadequately treated by the first application. These methods permitted the treatment of larger areas with the same number of planes, provided more protection to young shoot growth, and gave more assurance of completing the operation with at least one application well ahead of pupation.

In timing the earliest spraying of 1953 , it was necessary to consider foliage development as it affected larval concealment, in addition to insect development. In the spring the budworm first mines needles and unopened buds; later feeding takes place on the expanding shoots. From studies in Ontario, McGugan (12) concluded that "the basic pattern of needle mining activity on balsam fir trees was the same irrespective of widely divergent weather conditions". Studies that are still in progress in New Brunswick have shown that the relative proportions of larvae mining needles and buds varies from place to place and year to year, possibly under the influence of foliage age and vigor, the effects of frosts, and other climatic factors. (Another important factor, the effect of heavy flowering, discussed by Blais (7), has not yet been encountered in the severely defoliated stands under study.) In general, however, practically all the larvae are mining buds by the time the needles begin to flare at about the peak of the third instar. Following this the shoots open rapidly and the larvae become relatively well exposed to the contact effects of the spray. Therefore, satisfactory results from spraying are more likely to occur after the needles of the shoots become noticeably fiared.

Studies of results in 1953 showed that significant amounts of foliage were protected by spraying as early as the peak of the third instar although 
larval survival was relatively high. On areas receiving two applications approximately three weeks apart, final assessment showed both good foliage protection and high per cent mortality. Initial spraying near the end of the operation also reduced budworm populations to very low numbers, but very little current foliage was saved and feeding on old foliage had commenced in some cases (5).

One of the technical difficulties of assessing insect and foliage development in 19.53 and 1954 was the large area involved. Phenological differences of up to 13 days in early instar development were observed in sprayed areas in 1953. Intensive plot studies can be made at only a few locations and cannot represent the full range of variations that are certain to occur over an area of 2,800 square miles. Using the data from carefully selected points as basic information, it has been found possible to judge corresponding stages of development in other less accessible areas by observing the color of balsam fir foliage from low-flying aircraft. During a short period when balsam fir buds begin to flare, the peripheries of the tree crowns appear light yellow in contrast to the darker green of the older foliage. From the air, this is evident for only a few days before the new foliage assumes its normal color, and is apparent first in the tops of the crowns and later towards the bases. This is not necessarily due to shoot growth occurring in this sequence but probably to the greater concentration of vegetative and flower buds in the tops of the crowns. The 1953 operation was started when the light color was evident to the bases of the crowns. This was found to coincide closely with the peak of the third instar.

An additional modification in scheduling was introduced in 1954, by spraying alternate blocks first and returning later to complete the coverage. This is believed to take fuller advantage of the tendency of drift to affect adjacent blocks, but is only practical where it does not unduly complicate the aerial inspection of spraying operations. Other factors being equal, the most severely defoliated stands are considered ready for treatment earlier than others owing to the more rapid exposure of larvae feeding in the weaker, sparser shoots and the desirability of arresting the destruction of new shoots as early as possible.

\section{ANalysis of EFfects of Timing}

The following is an analysis of data from studies made in the 1954 sprayed areas to show the influence of timing on the total immediate effectiveness of spraying against the spruce budworm. The factors considered in "total effectiveness" are per cent reduction of the budworm population and per cent preservation of the current year's foliage of balsam fir.

Data for assessing immediate results were obtained from six sprayed plots set up for studies of population trends and 33 additional plots on which only counts of survivors were made. In addition, counts of missing 1954 shoots were made on all plots and estimates made of per cent defoliation of remaining shoots. Samples consisted of one mid-crown branch from each of five co-dominant balsam firs in each plot. The final count of survivors was made when about 20 per cent of the adults had emerged, three to six weeks after spraying. Populations were expressed in terms of branch area and for 
calculating per cent control were compared with similar data from an unsprayed check area (19).

For this analysis the data were grouped according to the number of days spraying occurred after the peak of the third instar. Table 2 shows the mean actual percentages of mortality and foliage preserved, by groups. A straight-line curve of percentage mortality and a second-degree polynomial curve of per cent foliage saved were calculated from the actual data. These are plotted in Figure 2. An estimate of total effectiveness was then obtained by adding values from each curve, assuming equal weight for budworm control and preservation of foliage. Table 3 shows that the sum of the extrapolated values equals 0 at approximately five days before and 25 days after the peak of the third instar. Total effectiveness at any spraying date was rated as a percentage of the maximum effectiveness value, 142.

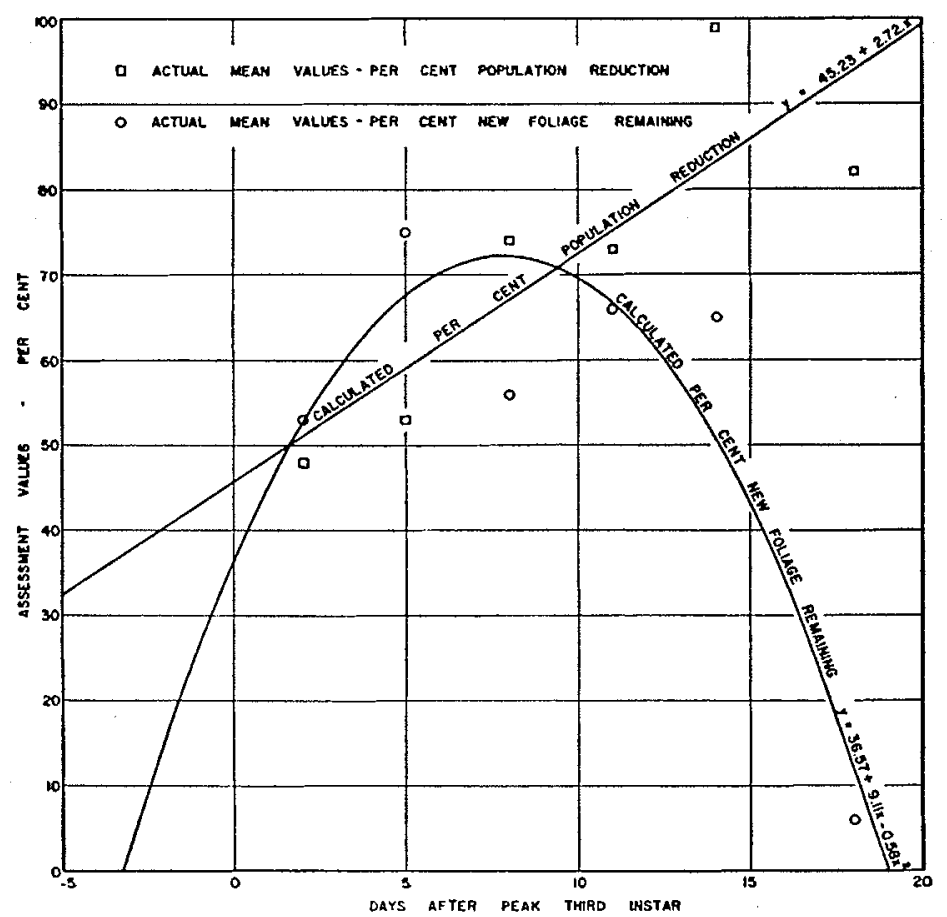

FIGURE 2

Regression of per cent population reduction from spraying and per cent foliage remaining-1954 spraying operation. 
TABLE 2

Summary of 1954 Sampling Data From Miramichi Sprayed Plots, Showing Actual Mean Values and Calculated Regression Values of Per Cent Population Reduction by Spraying and Per Cent New Foliage Remaining

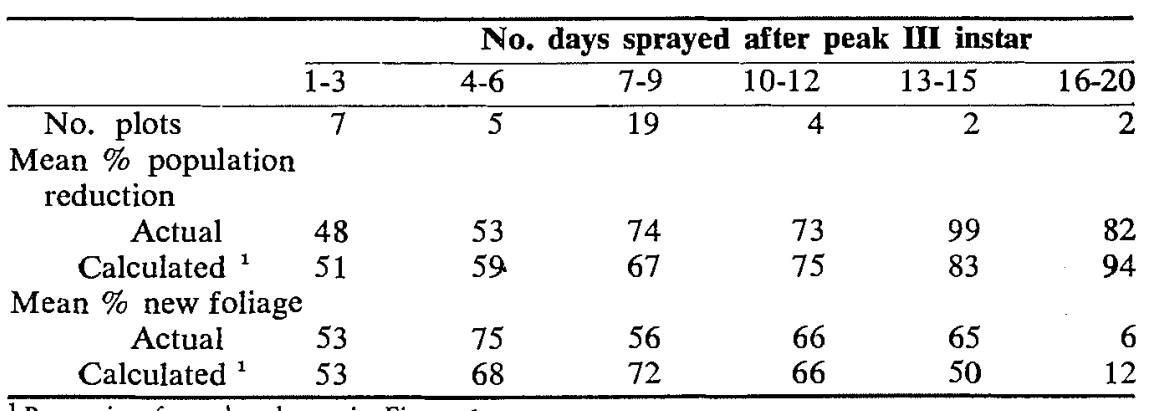

${ }^{1}$ Regression formulae shown in Figure 1.

TABLE 3

Partial Table of Regression Values of \% Population Reduction from SPRaying and \% New Foliage Remaining, Showing Method of Calculating \% Rated Effectiveness, Assuming Equal Weight for Degree of Budworm Control and Protection of New foliage.

\begin{tabular}{|c|c|c|c|c|}
\hline 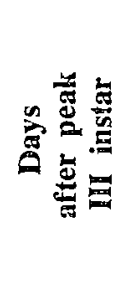 & 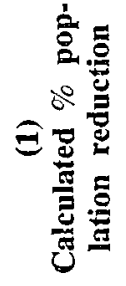 & 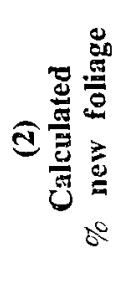 & $\widehat{a} \frac{a}{a}+$ & 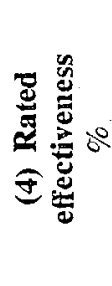 \\
\hline-5 & 31.6 & -31.0 & 0.6 & 0.4 \\
\hline 0 & 45.2 & 36.6 & 81.8 & 57.6 \\
\hline 5 & 58.8 & 67.6 & 126.4 & 89.0 \\
\hline 10 & 72.4 & 69.5 & 141.9 & 99.9 \\
\hline 15 & 86.0 & 42.4 & 128.4 & 90.4 \\
\hline 20 & 99.6 & -13.9 & 85.7 & 60.4 \\
\hline 25 & 100.0 & -99.2 & 0.8 & 0.6 \\
\hline
\end{tabular}



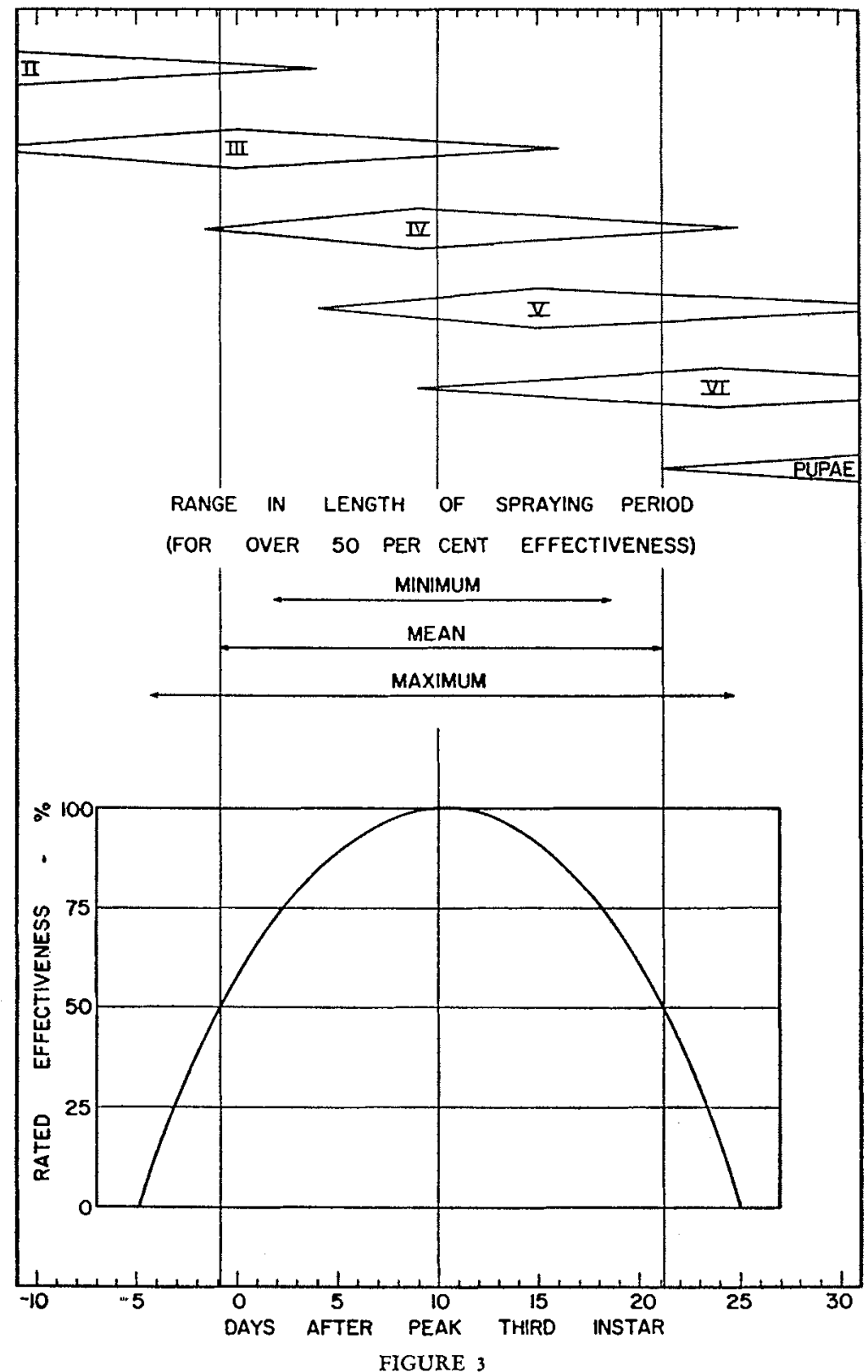

Approximate effectiveness of spraying against the spruce budworm under conditions of severe infestation plotted against instar development. Effectiveness curve calculated assuming equal weight for population reduction and foliage protection. 
The curve of rated effectiveness in per cent plotted against average instar development for northern New Brunswick is shown in Figure 3. According to this, spraying at the peak of the third instar resulted in 50 per cent effectiveness. The curve rises to the maximum value one day after the peak of the fourth instar and declines to 50 per cent effectiveness again by the commencement of pupation. The reasons for the rise and decline are evident from examination of the curves in Figure 2. Early spraying results in relatively low budworm control and poor foliage protection owing to the concealment of larvae in unopened shoots and continuation of defoliation by the survivors after spraying. Total effectiveness declines later in the spraying program, in spite of high larval mortality, owing to the destruction of foliage previous to spraying in late-sprayed areas.

TABLE 4

Probable Lengths of Spraying Periods for Various Percentages of Rated Effectiveness. Data from NORTHERN NEW BRUNSWICK

\begin{tabular}{cccc}
\hline $\begin{array}{c}\text { Per Cent } \\
\text { rated } \\
\text { effectiveness }\end{array}$ & \multicolumn{3}{c}{ Probable length of period - days } \\
\cline { 2 - 4 } & Minimum & Mean & Maximum \\
\hline 50 & $\mathbf{1 7}$ & 22 & 29 \\
60 & 15 & 20 & 26 \\
70 & 13 & 17 & 22 \\
80 & 11 & 14 & 18 \\
90 & 8 & 10 & 13 \\
\hline
\end{tabular}

Using the results of the 1954 operation and average development data from other years and other parts of northern New Brunswick, the probable range of days available for spraying operations in this region has been calculated and listed in Table 4. Fifty per cent or greater effectiveness has been possible for a period of from 17 to 29 days, averaging 22 days. For 90 per cent effectiveness, the period is slightly less than half that for 50 per cent, averaging 10 days.

\section{REFERENCES}

1. ANONYMOUS. 1952. Experimental airplane for spruce budworm control-1951. Unpublished combined report, U.S.D.A. Bureau of Entomology and Plant Quarantinc, Quebec Bureau of Entomology, Maine Forest Service, April 1, 1952.

2. BALCH, R. E. 1952. Aerial spraying in New Brunswick. Bi-Mon. Prog. Rept., Can. Dept. Agr., Div. For. Biol, B(4):1.

3. BALCH, R. E. 1952. The spruce budworm and aerial forest spraying. Can. Geog. Jour. 45(5):201-209.

4. BALCH, R. E. 1953. Current practices and future trends in forest insect control. For. Chron. 29(1):6-13.

5. BALCH, R. E., F. E. WEBB, and R. F. MORRIS. 1954. Results of spraying against spruce budworm in New Brunswick. Bi-Mon. Prog. Rept., Can. Dept. Agr., Div. For Biol. 10(1):1-2.

6. BELYEA, R. M. 1952. Death and deterioration of balsam fir weakened by spruce budworm defoliation in Ontario. Part II. An assessment of the role of associated insect species in the death of severely weakened trees. Jour. For. 50(10):729-738. 
7. BLAIS, J. R. 1952. The relationship of the spruce budworm (Choristoneura fumiferanta (Clem.) ) to the flowering condition of balsam fir (Abies balsamea (L.) Mill.). Can. Jour. Zool. 30:1-29.

8. BROWN, N. R. 1949. Lake Nipigon spraying operation. In Report on the use of DDT in the control of forest insects. Bi-Mon. Prog. Rept., Can. Dept. Agr., Sci. Ser., Div. Ent., $2(1): 1-3$. 1946. Also in Forest spraying and some effects of DDT, Biol. Bull. 2, Dept. Lands and Forests, Ontario. Div. Research, pp. 71-78.

9. EATOON, C. B., J. A. BEAL, R. L. FURNISS and C. F. SPEERS. 1949. Airplane and helicopter spraying with DDT for spruce budworm control. Jour. For. 47 (10):823-827.

10. FLIEGER, B. W. 1953. Spruce budworm spraying project in New Brunswick, 1953. Bi-Mon. Prog. Rept., Can. Dept. Agr., Div. For. Biol. 9(5):1-2.

11. FLIEGER, B. W. 1953. Forest protection from the spruce budworm in New Brunswick. Eighty-fourth Ann. Rept., Ent. Soc., Ont., pp. 9-16.

12. McGUGAN, B. M. 1954. Needle-mining habits and larval instars of the spruce budworm. Can. Ent. $86(10): 439-454$.

13. MORRIS, R. F. 1951. Effects of flowering on the foliage production and growth of balsam fir. For. Chron. $27(\mathrm{I}): 40-57$.

14. MORRIS, R. F. 1954. A sequential sampling technique for spruce budworm egg surveys. Can. Jour. Zool. 32:302-313.

15. NAGEL, R. H. 1946. Aerial application of DDT for spruce budworm control. In Report on the use of DDT in the control of forest insects. Bi-Mon. Prog. Rept., Can. Dept. Agr., Sci. Ser., Div. Ent. $2(1): 5-6$.

16. REEKS, W. A., R. S. FORBES, F. G. CUMING. 1949. Maritime Provinces and Newfoundland. In Ann. Rept. Forest Insect Survey, 1948. Can. Dept. Agr., Div. Ent., Sci. Ser., pp, 9-26,

17. STEWART, K. E. 1946. Results of studies on the application of DDT sprays from aircraft for the control of the spruce budworm in Quebec during 1945. In Report on the use of DDT in the control of forest insects. Bi-Mon. Prog. Rept., Can. Dept Agr., Div. Ent., 2(1):4-5.

18. STEWART, K. E. 1949. Application of DDT sprays by aircraft in Canada for the control of the spruce budworm, Archips fumiforana Clem. In Forest spraying and some effects of DDT, Biol. Bull. 2, Dept. Lands and Forests, Ontario, Div. Research, Pp. 93-140.

19. WEBB, F. E. 1955. Aerial spraying against spruce budworm in New Brunswick, 1954. Bi-Mon. Prog. Rept., Can. Dept. Agr., Div. For. Biol. 11 (1):1-2. 